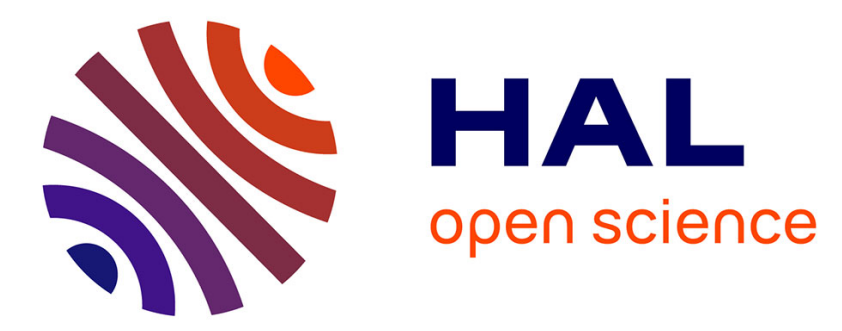

\title{
Doxorubicin-induced suppression of poly(ADP-ribose) polymerase-1 (PARP-1) activity and expression and its implication for PARP inhibitors in clinical trials
}

Tomasz Zaremba, Huw Thomas, Michael Cole, Elizabeth R. Plummer, Nicola J. Curtin

\section{To cite this version:}

Tomasz Zaremba, Huw Thomas, Michael Cole, Elizabeth R. Plummer, Nicola J. Curtin. Doxorubicininduced suppression of poly(ADP-ribose) polymerase-1 (PARP-1) activity and expression and its implication for PARP inhibitors in clinical trials. Cancer Chemotherapy and Pharmacology, 2010, 66 (4), pp.807-812. 10.1007/s00280-010-1359-0 . hal-00594821

\section{HAL Id: hal-00594821 \\ https://hal.science/hal-00594821}

Submitted on 21 May 2011

HAL is a multi-disciplinary open access archive for the deposit and dissemination of scientific research documents, whether they are published or not. The documents may come from teaching and research institutions in France or abroad, or from public or private research centers.
L'archive ouverte pluridisciplinaire HAL, est destinée au dépôt et à la diffusion de documents scientifiques de niveau recherche, publiés ou non, émanant des établissements d'enseignement et de recherche français ou étrangers, des laboratoires publics ou privés. 


\title{
Doxorubicin-induced suppression of poly(ADP-ribose) polymerase-1 (PARP-1) activity and expression and its implication for PARP inhibitors in clinical trials
}

\author{
Tomasz Zaremba $\cdot$ Huw Thomas $\cdot$ Michael Cole $\cdot$ \\ Elizabeth R. Plummer $\cdot$ Nicola J. Curtin
}

Received: 9 February 2010 / Accepted: 1 May 2010 / Published online: 21 May 2010

(C) Springer-Verlag 2010

\begin{abstract}
Purpose Monozygotic twins provide an excellent tool to study environmental effects on human health. Poly(ADPribose) polymerase-1 (PARP-1) is an important enzyme primarily involved in DNA repair and genomic stability and is under clinical investigation as a target for anticancer therapy. As a part of a PARP pharmacogenetics study, elderly male monozygotic twins, one healthy and the other with a Trojani grade 3 sarcoma treated with doxorubicin (DOX: $142.5 \mathrm{mg} / \mathrm{m}^{2}$ ), were recruited for the study.

Methods PARP activity and expression were measured in peripheral blood mononuclear cells (PBMCs) by methods validated to GCLP standard and used as a pharmacodynamic endpoint for clinical trials.

Results The mean PARP activity for the patient before treatment was 160 pmol PAR $/ 10^{6}$ cells and was similar to that of his brother $\left(130\right.$ pmol PAR $/ 10^{6}$ cells). There was approximately ninefold decrease $(P=0.001)$ in PARP activity in a second sample from the patient taken 21 days after the first DOX administration (17 pmol PAR $/ 10^{6}$ cells) and a decrease in PARP-1 expression. Investigations into $\mathrm{BALB} / \mathrm{C}$ mice revealed that DOX treatment $(5 \mathrm{mg} / \mathrm{kg})$ resulted in a significant transient decrease in PARP activity
\end{abstract}

T. Zaremba $\cdot$ H. Thomas $\cdot$ M. Cole $\cdot$ E. R. Plummer .

N. J. Curtin ( $\square)$

Northern Institute for Cancer Research,

Newcastle University, Paul O'Gorman Building,

Newcastle upon Tyne NE2 4HH, UK

e-mail:n.j.curtin@ncl.ac.uk

T. Zaremba

Department of Clinical Biochemistry,

Nicolaus Copernicus University Collegium Medicum,

Bydgoszcz, Poland after $1 \mathrm{~h}(63 \%$ control, $P \ll 0.05)$ and $24 \mathrm{~h}(53 \%$ control, $P \ll 0.05)$ but that PARP activity was restored 1 week after DOX treatment ( $86 \%$ control, $P=0.24$ ).

Conclusions We showed here that administration of DOX can have a profound effect on the measured level of PARP activity and expression in PBMCs from patients and animals. Results obtained in clinical trials where PARP activity is used as a pharmacodynamic marker of PARP inhibition could reflect the effect of a chemotherapeutic on PBMCs rather than the effectiveness of a tested PARP inhibitor.

Keywords PARP-1 PARP-1 activity ·

PARP-1 expression · PARP inhibitors · Doxorubicin .

Monozygotic twins

\section{Introduction and aims}

Monozygotic twins, due to identical genetic constitution, uterine and early environment, provide an excellent material to study the contribution of genes and the environment on human biochemistry, pharmacology and health. Twin studies can help to identify underlying causes of both physical and mental disorders [1] and response to drugs [2]. Large, nationwide twin studies can help to define the contributions of nature and nurture to complex and multifactorial diseases such as cancer [3]. The identification of areas of study likely to be worth investing the substantial resources needed for the larger studies comes from initial interesting sporadic observations. Here, for the first time, we investigated PARP activity and expression in monozygotic twin brothers excluding any potential genetic factors that could affect levels of measured parameters. As a part of a pharmacogenetics study, the elderly male twins, one with a 
sarcoma that was treated with doxorubicin (DOX) and the other healthy, were recruited to the study.

Soft tissue sarcomas are rare types of cancer accounting for about $1 \%$ of adult malignancies (http://www.macmillan. org.uk/Cancerinformation/Cancertypes/Softtissuesarcomas/). Sarcomas are usually treated by a surgical excision either alone or in combination with radiotherapy. There are only three drugs, DOX, dacarbazine and ifosfamide, currently used in treatment that give a relatively good response rate of $20 \%$ or more in patients with advanced soft tissue sarcomas [4].

DOX (also called adriamycin) is one of the most widely used anticancer agents and has the broadest spectrum of activity involving DNA intercalation, free-radical formation, covalent DNA binding and inhibition of the topoisomerase II resulting in DNA strand breakage. DOX is a widely prescribed chemotherapeutic used to treat many different types of cancers; however, its use in high doses is limited by the occurrence of severe side effects such as cardiotoxicity, myelotoxicity and Palmar-plantar erythrodysesthesia [5].

Poly(ADP-ribose) polymerase-1 (PARP-1) is a DNAbinding enzyme activated by DNA single-strand and double-strand breaks and involved in DNA repair, genomic stability, transcription control, cell death and proliferation. Inhibition, or lack, of PARP-1 results in hyper-sensitivity to DNA methylating agents, topoisomerase I poisons and ionising radiation, all used in the treatment of cancer [6]. Recent in vivo studies demonstrate that PARP inhibition potentiates the antitumour effects of DOX in p53-deficient human breast cancer [7].

Analysis of the samples received from the twin subjects allowed us to investigate the inter-individual variation in PARP activity in subjects with the same genetic background, and we could also investigate how DOX affects PARP activity in peripheral blood mononuclear cells (PBMCs). The observed decrease in PARP activity following DOX treatment in the patient was then studied in vivo in mice treated with DOX.

\section{Materials and methods}

All chemicals and reagents were of the highest quality and supplied by Sigma (Dorset, UK), unless indicated otherwise. The PARP inhibitor AG014699 was supplied by Pfizer GRD. The $10 \mathrm{H}$ mouse monoclonal primary antibody was generously supplied by Prof. Alexander Bürkle (University of Konstanz, Germany).

\section{Human subjects}

The PARP pharmacogenetics study has been reviewed by the appropriate ethics committee and has been performed in accordance with the ethical standards laid down in the 1964 Declaration of Helsinki. The patient and his healthy twin brother (control subject) were consented to donate blood samples under the regulations of local ethics committee. A volume of $20 \mathrm{ml}$ or less of whole blood was collected from the subjects by venipuncture. Blood from the patient was collected just before the first administration of chemotherapy and 21 days after the first administration, just before second cycle of treatment. This was transferred into EDTA blood tubes (BD Vacutainer, Plymouth, UK). PBMCs were then extracted from blood using Lymphoprep ${ }^{\mathrm{TM}}$ Tube (Axis-Shield, Norway) according to manufacturer's instructions. The cell pellet was resuspended in $500 \mu \mathrm{l}$ prechilled freezing medium (RPMI plus $10 \%$ foetal bovine serum, FBS), supplemented with $10 \%$ DMSO, and $1 \times$ Halt protease inhibitor cocktail (Thermo Fisher Scientific, Rockford, IL). Samples were stored immediately at $-80^{\circ} \mathrm{C}$.

\section{Animals}

The experiments on animals were conducted in accordance with national law and institutional guidelines for the care and use of animals under a protocol approved by local ethics committee. Male BALB/C mice (8-10 weeks of age, 5 mice/group) were treated as follows: untreated controls and mice treated with $5 \mathrm{mg} / \mathrm{kg}$ DOX via intraperitoneal injection (IP) and killed $1 \mathrm{~h}, 24 \mathrm{~h}$ and 6 days after treatment. Blood from the five animals was pooled to yield sufficient sample for lymphopreparation and collected into tubes containing an anticoagulant (EDTA) and stored on ice for up to $2 \mathrm{~h}$ prior to further processing. Blood was then diluted 1:1 with phosphate buffered saline (PBS) $6 \mathrm{ml}$ was layered over $3 \mathrm{ml}$ of Lymhoprep (Axis-Shield, Norway) and processed according to manufacturer's instruction.

\section{Measurement of PARP activity}

PARP activity was measured by modification of a previously described method [8] validated to GCLP standard and used as a pharmacodynamic endpoint for clinical trials [9]. Briefly, maximally stimulated PARP activity was measured in triplicate samples of $10^{4}$ cells permeabilised with icecold digitonin $(0.15 \mathrm{mg} / \mathrm{ml}$ in water) in a reaction mixture containing $350 \mu \mathrm{mol} / 1 \mathrm{NAD}^{+}$as substrate in excess and $10 \mu \mathrm{g} / \mathrm{ml}$ PARP-activating oligonucleotide (CGGAATT CCG) (Europrim, Invitrogen, UK) that mimics DNA strand breaks, in a reaction buffer of $100 \mathrm{mmol} / \mathrm{l}$ Tris- $\mathrm{HCl}$ and $120 \mathrm{mmol} / 1 \mathrm{MgCl}_{2}$ (pH 7.8) in a final volume of $100 \mu \mathrm{l}$ at $26^{\circ} \mathrm{C}$ in an oscillating water bath. The use of an oligonucleotide to maximally stimulate PARP minimises variation due to accidental activation of PARP by the unintentional induction of DNA breaks during PBMC harvesting and 
processing. The reaction was stopped after $6 \mathrm{~min}$. by the addition of excess PARP inhibitor $(400 \mu \mathrm{l}$ of $12.5 \mu \mathrm{mol} / \mathrm{l}$ AG014699), and the cells were blotted along with a poly(ADP-ribose) standard (0-25 pmol: Biomol, Exeter, UK) onto a nitrocellulose membrane (Hybond-N, Amersham, UK) using a purpose-built 48-well manifold. Following incubation with the primary anti-PAR $10 \mathrm{H}$ antibody $1: 500$ in PBS containing 5\% non-fat powdered dried milk and $0.5 \%$ Tween 20 (PBS-MT) overnight at $4{ }^{\circ} \mathrm{C}$ then HRP-conjugated goat anti-mouse secondary antibody $(1: 1,000$ in PBS-MT; Dako, Ely, UK) for $1 \mathrm{~h}$ at room temperature, the membrane was exposed for $1 \mathrm{~min}$. to enhanced chemiluminescence (ECL) reaction solution (Amersham, Little Chalford, UK), and chemiluminescence was measured using a Fuji LAS3000 with imaging software (Fuji LAS Image version 1.1, Raytek). Results were expressed in light absorbtion units (LAU) relative to the number of cells loaded and subsequently calculated by reference to the poly(ADPribose) standard curve.

\section{Measurement of PARP-1 expression}

Briefly, the cell pellet was lysed in $100 \mu$ of Laemmli buffer [10] with $1 \times$ Halt protease inhibitor cocktail (Thermo Fisher Scientific) resuspended on ice for $30 \mathrm{~min}$. sonicated on ice for $10 \mathrm{~s}$ (Vibracell Sonicator, Sonics and Materials, Danbury, Conn.) and heated in loading dye containing $\beta$-mercaptoethanol and bromophenol blue at $95^{\circ} \mathrm{C}$ for $5 \mathrm{~min}$. Lysates ( $30 \mu \mathrm{g}$ of protein per lane) were loaded onto Tris- $\mathrm{HCl} 5-20 \%$ polyacrylamide gels (BioRad, Hercules, CA) along with purified recombinant PARP-1 immunoblotting standard (Biomol, Exeter, UK), and after electrophoresis at $100 \mathrm{~V}$ for $2 \mathrm{~h}$ (Criterion electrophoresis apparatus, Bio-Rad), the proteins were transferred for $1 \mathrm{~h}$ at $4^{\circ} \mathrm{C}$ into a nitrocellulose membrane (Hybond-C, Amersham, UK) using a Criterion Blotter (Bio-Rad). After blocking for $1 \mathrm{~h}$ in PBS-MT, the membrane was incubated overnight at $4{ }^{\circ} \mathrm{C}$ with shaking with an anti-PARP-1 C2-10 primary antibody (Trevigen, Gaithersburg, MD) diluted 1:2,000 in PBS-MT, washed 3 times for $15 \mathrm{~min}$. in PBS containing $0.5 \%$ Tween 20 (PBS-T) and then incubated with the HRP-linked secondary goat anti-mouse antibody (Dako) diluted 1:1,000 in PBS-MT, washed again for $1 \mathrm{~h}$ in PBS-T with changing buffer every $5 \mathrm{~min}$. and then dried. The protein was visualised with ECL plus detection kit (Amersham) using the manufacturer's protocol followed by chemiluminescence detection as described above. We quantified the PARP-1 expression by reference to purified recombinant PARP-1 protein (Biomol) standard curve $(0-40 \mathrm{ng})$. This assay has also been validated to GCLP standard for evaluation of patient samples (E. Mulligan and T. Zaremba, unpublished data).
Statistical analysis

We analysed each pooled sample in triplicate in three independent experiments (animals) or in duplicate (Western blot) and quadruplicate (PAR assay) in single experiment (humans). We calculated $P$ values for PARP activity comparison by the Student's $t$ test using GraphPad Prism4 software (GraphPad, La Jolla, CA) and by Tukey's test (Minitab, Coventry, UK).

\section{Results}

\section{Case presentation}

A 67-year-old male patient presented in 2006 with a $7-8 \mathrm{~cm}$ left proximal vastus medialis mass in the left thigh mass, which on incision biopsy showed a Trojani grade 3 soft tissue sarcoma of non-specific type, and no evidence of metastatic disease. Subsequently, the patient had surgery to remove the tumour and received adjuvant radiotherapy (60 Gy in 30 fractions). In 2007, pulmonary metastases and intra-abdominal lymphadenopathy were detected, and the patient received single agent DOX $\left(142.5 \mathrm{mg} / \mathrm{m}^{2}\right)$. Before the first cycle of chemotherapy, the patient was consented for study. A blood sample was obtained and processed according to local ethics committee. The patient revealed that he had an identical twin brother who would be willing to donate a blood sample for the study as a healthy volunteer. The sample was obtained at the same time as the second sample from patient, which took place 3 weeks after administration of the first dose of DOX.

\section{PARP activity}

Measurement of PARP activity in PBMCs from the subjects showed that the mean PARP activity for the patient before the treatment was $160 \mathrm{pmol} \mathrm{PAR} / 10^{6}$ cells and that for the healthy volunteer was 130 pmol PAR $/ 10^{6}$ cells. We observed an approximately ninefold decrease in PARP activity in a second sample from the patient taken 21 days after the first drug administration (17 pmol PAR $/ 10^{6}$ cells) (Fig. 1a, b).

\section{PARP-1 expression}

Measurement of PARP-1 expression in PBMCs from the subjects showed that the mean expression for the patient before the treatment was $0.15 \mathrm{ng} \mathrm{PARP} / \mu \mathrm{g}$ total cellular protein while for the healthy volunteer was $0.2 \mathrm{ng}$ PARP/ $\mu \mathrm{g}$ total cellular protein. We observed a decrease in PARP-1 expression to below the limit of quantification in the patient sample taken after the first cycle of DOX treatment (Fig. 1c). 

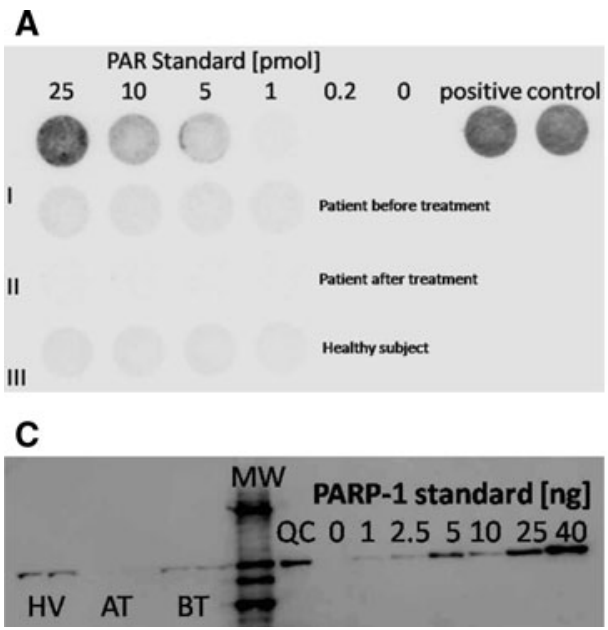

Fig. 1 PARP activity and expression measured in PBMCs from the patient before and after first cycle of DOX treatment and from the healthy volunteer (control subject). a PAR formation detected by immunoblot assay. First row of dots shows results for 25, 10, 5, 1, 0.2, 0 pmol PAR standard and positive reaction for quality control sample of L1210 cells (positive control). Dots in rows I-II show PAR formation in PBMCs from the patient before and after DOX treatment, row III shows PAR formation in PBMCs from healthy subject. b Semiquantitative analysis of the results of the experiment shown in $\mathbf{a}$ : mean

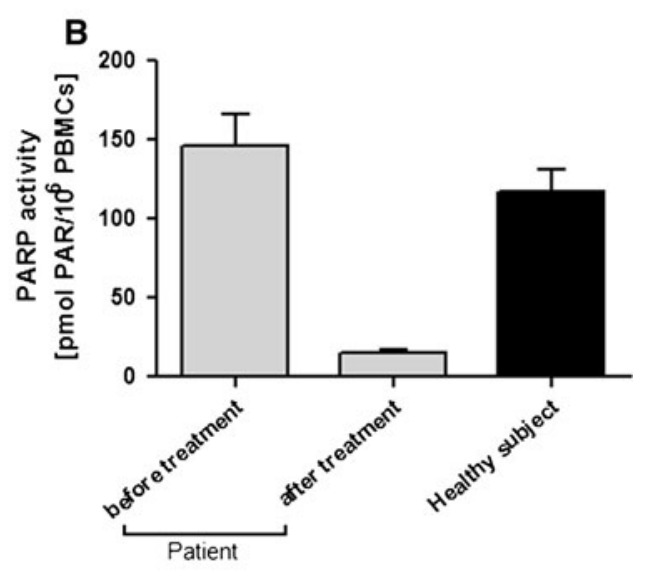

value for data from single experiment where each sample was measured in quadruplicate, error bars represent SEM. c PARP-1 expression measured by semi-quantitative Western blot. Bands on the left-hand side of the blot: $B T$, patient's sample taken before DOX treatment; $A T$, patient's sample taken after DOX treatment; $H V$, healthy volunteer's (sibling) sample. Bands on the right-hand side of the blot: positive reaction for quality control $(Q C)$ sample of $\mathrm{K} 562$ cells and $0,1,2.5,5$, $10,25,40 \mathrm{ng}$ of recombinant PARP-1 standard. $M W$, molecular weight marker
Fig. 2 Effects of DOX treatment on the PARP activity in PBMCs from male mice. a PAR formation detected by immunoblot assay. b Analysis of the results from three independent experiments where samples are assayed in triplicate. Data are expressed as percentage control
A

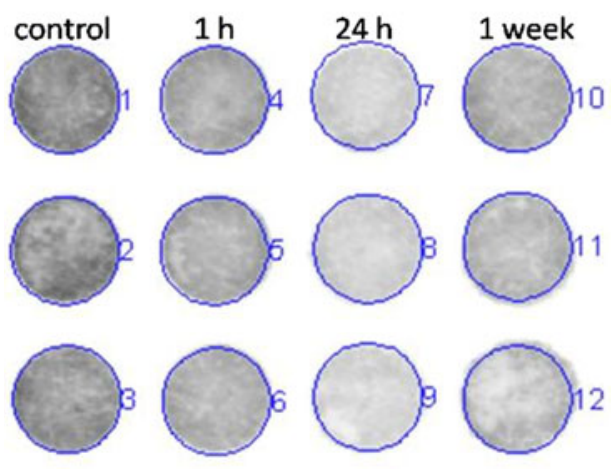

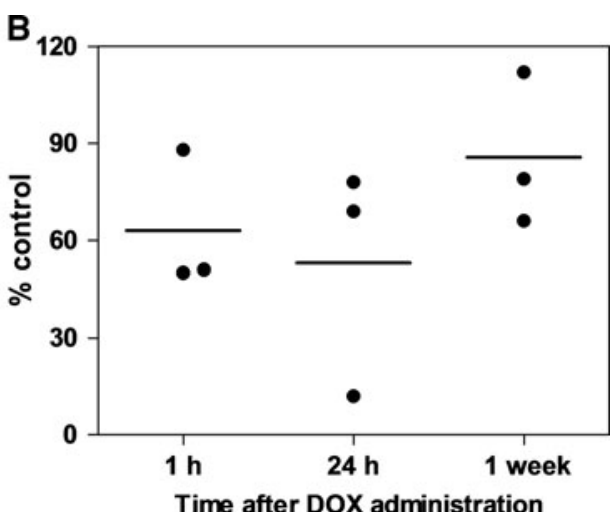

PARP activity in mice treated with DOX

The effects of DOX treatment $(5 \mathrm{mg} / \mathrm{kg})$ on PARP activity in PBMCs from mice $1 \mathrm{~h}, 24 \mathrm{~h}$ and 1 week after drug administration are shown in Fig. 2. We observed decrease in PARP activity $1 \mathrm{~h}$ after drug administration (63\% control, range 50$88 \% ; P \ll 0.05$, Tukey's test) and after $24 \mathrm{~h}$ (53\% control, range $12-78 \% ; P \ll 0.05$, Tukey's test). We observed restoration in PARP activity 1 week after DOX treatment $(86 \%$ control, range 66-112\%; $P=0.24$, Tukey's test).

\section{Discussion}

In this study, we investigated the inter-individual variation in PARP activity and expression in subjects with the same genetic background i.e. homozygotic twins. We found that in the patient's pre-treatment sample, PARP activity and expression were similar to his identical brother. In both subjects, PARP activity was within the range seen in the general population of healthy volunteers and cancer patients (10-2190 pmol/10 ${ }^{6}$ cells: TZ unpublished data). We showed that an identical genotype gave very similar phenotype, and this finding must be taken into account in an ongoing discussion about the factors determining PARP activity in relation to PARP-1 expression in humans.

We also found that after DOX treatment, the patient had much lower PARP activity and PARP-1 expression. This observation suggested that DOX treatment may reduce both parameters.

To confirm our findings, we also investigated DOX treatment in an animal model: PARP activity was also 
suppressed in male mice treated with DOX $(5 \mathrm{mg} / \mathrm{kg}) 1$ and $24 \mathrm{~h}$ after drug administration $(P \ll 0.05)$. However, the effect was more modest (approximately twofold) compared to the substantial (ninefold) reduction in the patient.

Our finding with a decrease in PARP activity after DOX treatment is somewhat in contrast with previous data showing that cardiotoxicity of DOX is a result of oxidative stress (reactive oxygen species, ROS formation) where oxidative DNA breakage leads to PARP activation [11]. We hypothesise that DOX treatment, due to its selective toxicity to different subtypes of blood cells, altered the profile of the PBMC (mostly lymphocytes) population and that the observed decrease in PARP activity could be due to selective killing of the population of cells with higher PARP activity by DOX. Ranjit et al. [12] showed that different subtypes of PBMCs had different PARP-1 content with B lymphocytes (18-47\% of lymphocytes) having the highest expression level (8.64 Units), compared with $\mathrm{T}$ lymphocytes (approx. 70\% of lymphocytes, 4.2 Units) and monocytes (3-8\% of leucocytes, 2.2 Units). If the reason for high PARP-1 expression in B lymphocytes is associated with its role in DNA rearrangement necessary for the production of antibodies, PARP activity in B cells may also be high. At least two studies showed that chemotherapy causes significant reduction in B lymphocyte count. Mackall et al. [13] demonstrated a rapid and severe decrease in B cell number to almost undetectable level after one cycle of chemotherapy (several different regimes including single-agent cyclophosphamide and cyclophosphamide in combination with DOX and vincristine) and up to sixfold decrease in number of $\mathrm{T}$ cells in 10 studied patients. Similarly, Hakim et al. [14] showed up to $96 \%$ reduction in B cells and $>60 \%$ reduction in $\mathrm{T}$ cells after treatment with FLAC regime (DOX, 5-fluorouracil, cyclophosphamide). The full recovery in number of B lymphocytes was not observed until 3 months after the last cycle. These data suggest that chemotherapy leads to the depletion of several subtypes of PBMCs, especially B lymphocytes. The decrease in activity in the sarcoma patient treated with DOX could therefore be due to loss of PBMCs with high PARP-1 expression and PARP activity leaving the patient with those that naturally have less PARP-1 and lower activity. However, a larger study would be needed to confirm such an implication. The much greater effect of DOX in the patient than in the mice may reflect the time of sampling. If the high PARP-1expressing cells are culled in a time-dependent fashion, we may not have sampled the mouse PBMCs at the nadir and may have been only measuring the semi-acute effects of DOX on PARP activity rather than a combined effect on activity and selective killing of high PARP-1-expressing cells. Further experiments are clearly warranted to determine the time-dependent effects of DOX on lymphocyte populations with different PARP-1 expression.
This small study showed a profound decrease in PARP activity measured in PBMCs from a patient who underwent chemotherapy treatment. Our hypothesis that this could be due to a selective depletion of B lymphocytes in blood requires further investigation. This finding is very important for current and future clinical studies and trials on PARP inhibitors where PARP activity is used as a pharmacodynamic endpoint; here, we demonstrated that a decrease in PARP activity in such studies could be due to an effect of the chemotherapeutic, as well as the PARP inhibitor, on PBMCs and lead to a false impression of the effectiveness of the PARP inhibitor. As a potential solution it would be beneficial to perform flow cytometry analysis to test the content of different cell subtypes and subsequently measure PARP activity in those cells. The difference in PARP activity before and after drug administration would give a real picture of effectiveness of tested therapy and also information on its toxicity to particular cell subtypes.

Acknowledgments We thank Prof. Alexander Bürkle for $10 \mathrm{H}$ antibodies and Pfizer GRD for AG014699 inhibitor. TZ was supported by a studentship from AICR, and NJC is supported by Cancer Research UK.

\section{Conflict of interest statement None.}

\section{References}

1. Boomsma D, Busjahn A, Peltonen L (2002) Classical twin studies and beyond. Nat Genet 3:872-882

2. Ring HZ, Valdes AM, Nishita DM, Prasad S, Jacob P, Tyndale RF, Swan GE, Benowitz NL (2007) Gene-gene interactions between CYP2B6 and CYP2A6 in nicotine metabolism. Pharmacogenet Genomics 17:1007-1015

3. Pedersen NL, Lichtenstein P, Svedberg P (2002) The Swedish Twin Registry in the third millennium. Twin Res 5:427-432

4. Cormier NJ, Pollock RE (2004) Soft tissue sarcomas. CA Cancer J Clin 54:94-109

5. Demetri GD (1998) Major developments in the understanding and treatment of soft tissue sarcomas in adults. Curr Opin Oncol 10:343-347

6. Curtin NJ (2005) PARP inhibitors for cancer therapy. Expert Rev Mol Med 15:1-20

7. Mason KA, Valdecanas D, Hunter NR, Milas L (2008) INO-1001, a novel inhibitor of poly(ADP-ribose) polymerase, enhances tumor response to doxorubicin. Invest New Drugs 26:1-5

8. Plummer ER, Middleton MR, Jones C et al (2005) Temozolomide pharmacodynamics in patients with metastatic melanoma: dna damage and activity of repair enzymes $O$-6-alkylguanine alkyltransferase and poly(ADP-ribose) polymerase-1. Clin Cancer Res 11:3402-3409

9. Plummer R, Jones C, Middleton M, Wilson R et al (2008) Phase I study of the poly(ADP-ribose) polymerase inhibitor, AG014699, in combination with temozolomide in patients with advanced solid tumors. Clin Cancer Res 14:7917-7923

10. Laemmli UK (1970) Cleavage of structural proteins during the assembly of the head of bacteriophage T4. Nature 227:680-685

11. Pacher P, Liaudet L, Bai P, Virag L, Mabley JG, Hasko G, Szabo C (2002) Activation of poly(ADP-ribose) polymerase contributes to development of doxorubicin-induced heart failure. J Pharmacol Exp Ther 300:862-867 
12. Ranjit GB, Cheng MF, Mackay W et al (1995) Poly(adenosine diphosphoribose) polymerase in peripheral blood leukocytes from normal donors and patients with malignancies. Clin Cancer Res 1:223-234

13. Mackall CL, Fleisher TA, Brown MR et al (1994) Lymphocyte depletion during treatment with intensive chemotherapy for cancer. Blood 84:2221-2228
14. Hakim FT, Cepeda R, Kaimei S et al (1997) Constraints on CD4 recovery postchemotherapy in adults: thymic insufficiency and apoptotic decline of expanded peripheral CD4 cells. Blood 90:3789-3798 